\title{
DEVELOPMENT OF GEOSPATIAL MAP BASED PORTAL FOR NEW DELHI MUNICIPAL COUNCIL
}

\author{
Amit Kumar Chandra Gupta ${ }^{\mathrm{a}}$, Pawan Kumar ${ }^{\mathrm{b}}$, Pawan Kumar Sharma ${ }^{\mathrm{c}}$ \\ ${ }^{\mathrm{a}}$ Geospatial Executive - amitkc.gis@gmail.com, ${ }^{\mathrm{b}}$ Software Developer - pawankr82@gmail.com, \\ ${ }^{\mathrm{c}}$ Managing Director (IAS) - secyit@nic.in \\ Geospatial Delhi limited, Department of Information Technology, Ministry of Communications and Information Technology
}

KEY WORDS: Geospatial Map based Portal (GMP), New Delhi Municipal Council (NDMC), Spatial Decision Support System (SDSS), Virtual Private Network (VPN), Special Purpose Vehicle (SPV)

\begin{abstract}
:
The Geospatial Delhi Limited (GSDL), a Govt. of NCT of Delhi Company formed in order to provide the geospatial information of National Capital Territory of Delhi (NCTD) to the Government of National Capital Territory of Delhi (GNCTD) and its organs such as DDA, MCD, DJB, State Election Department, DMRC etc., for the benefit of all citizens of Government of National Capital Territory of Delhi (GNCTD).

This paper describes the development of Geospatial Map based Portal (GMP) for New Delhi Municipal Council (NDMC) of NCT of Delhi. The GMP has been developed as a map based spatial decision support system (SDSS) for planning and development of NDMC area to the NDMC department and It's heaving the inbuilt information searching tools (identifying of location, nearest utilities locations, distance measurement etc.) for the citizens of NCTD. The GMP is based on Client-Server architecture model. It has been developed using Arc GIS Server 10.0 with .NET (pronounced dot net) technology. The GMP is scalable to enterprise SDSS with enterprise Geo Database \& Virtual Private Network (VPN) connectivity.

Spatial data to GMP includes Circle, Division, Sub-division boundaries of department pertaining to New Delhi Municipal Council, Parcels of residential, commercial, and government buildings, basic amenities (Police Stations, Hospitals, Schools, Banks, ATMs and Fire Stations etc.), Over-ground and Underground utility network lines, Roads, Railway features. GMP could help achieve not only the desired transparency and easiness in planning process but also facilitates through efficient \& effective tools for development and management of MCD area. It enables a faster response to the changing ground realities in the development planning, owing to its in-built scientific approach and open-ended design.
\end{abstract}

\section{INTRODUCTION}

The National Capital Territory of Delhi (NCT) comprises three local bodies, MCD, NDMC and Cantonment Board. NDMC resolves to intensify its efforts in providing better civic services to the citizens and a multitude of visiting patrons from all over the country and overseas. Other objectives before NDMC are to improve quality of life provide social and community welfare amenities with public, private participation- with special emphasis on promotion of art \& culture, environmental improvement, cleaning \& greening campaigns to serve as a show window of "A Model Well-Planned Metropolitan City". NDMC is committed to develop the New Delhi area as a smart city and its Vision for Smart City is: "To be the Global Benchmark for a Capital City. The Geographical Information System (G.I.S.) could play a vital role for systematic, smooth and transparent functioning of departmental processes. GIS could facilitate to NDMC for planning, management and in all ways as a spatial decision support system (SDSS) with thematic map representation as well as map based web application by using the spatial \& non spatial data.

\subsection{Problem at Hand}

The creation, updation, maintenance and general management of MCD data (Demographic, Topographic, Utility etc.) in terms of spatial and non-spatial data is a herculean task. The voluminous nature of data involved for proper record keeping is indeed cumbersome and cannot effectively be handled by traditional system of record keeping. The analogue system means acceptance of inflexibility resulting from data storage in fixed forms and formats. The system becomes less useful for many purposes and is rarely updated because of costs implication. The maps are easily displaced or destroyed because different people at different locations use them. An alternative approach taking into the account of limitations faced by the traditional system is of maintaining a coherent database in a scientific and efficient manner by use of advanced information technology is therefore, required. Hence, there will be improvements in planning, implementation and operation of the NDMC department through provision of timely, reliable, sufficiently and accurately detailed data which will facilitate its decision making activities.

This paper describes the development of Geospatial Map based portal (GMP) of NDMC. The portal has been developed as a map based spatial decision support system (SDSS) for pertain to planning and management of New Delhi Municipal Council, and as a spatial information searching tools (Building address locations search, distance measurement and suitable path analysis for visiting etc.,) for the citizens of NCTD. It enables a faster response to the changing ground realities in the development planning, owing to its in-built scientific approach and open-ended design. The GMP is based on Client-Server architecture model. It has been developed using Arc GIS Server 10.0 with .NET on Microsoft Windows environment. The GMP is scalable to enterprise SDSS with enterprise Geo Database \& Virtual Private Network (VPN) connectivity. 


\section{STUDY AREA}

$28^{\circ} 36^{\prime} 50^{\prime \prime} \mathrm{N} 77^{\circ} 12^{\prime} 32^{\prime \prime} \mathrm{E}$ is the geographical location of New Delhi Municipal Council area in NCT of Delhi. It is further divided in 9 municipal wards.

\subsection{Spatial Data Dictionary}

Geospatial Delhi Limited (GSDL), a Govt. of NCT of Delhi Company, is a Geo-Knowledge enterprise, initially formulated as a Special Purpose Vehicle (SPV) to facilitate the Delhi State Spatial Data Infrastructure (DSSDI) Project. Each and every building and other spatial features (Like Buildings, Roads, Parks, Natural features etc) of NCT of Delhi has been captured in DSSDI project. The property data base was collected through field survey supplemented with concerned departmental inputs. This huge data is updating continuously by GSDL day by day. By using this data as a base layer and administrative data (Demographic non spatial data) of NDMC, GSDL has created the demographic and utility spatial layers (Zone, Sectors, Locality boundaries Layers, Electric, Gas, Water pipelines, telecommunication cable lines, offices). These features represent the essential components of spatial database over which all secondary spatial as well as non-spatial information are superimposed for query/analysis and generation of thematic maps.

\subsection{Spatial Database Creation}

As per the methodology and guidelines described above, stateof-the-art Arc GIS Server 10.0 has been used for creation of the required spatial database in digital form. The digitized map information is stored in the GIS database appropriately in the form of layers, each layer representing a unique entity in the spatial data dictionary.

\section{GIS PLATFORM}

ESRI Arc GIS Server 10.0 provides a standard framework for developing GIS applications. Arc GIS Server is both robust and extensible and its rich functionality allows developers to concentrate on solving organizational problems, not building GIS functionality from scratch. Arc GIS Server is based on Object oriented Framework. Arc GIS Server Objects support for simple map dialog boxes, multithreaded servers, and complex Windows desktop applications.

\subsection{Key features of Arc GIS Server}

Cost-effective deployment: Arc GIS Server Runtime is licensed per computer. This allows multiple Arc GIS applications to run on the same computer, incurring the cost of only a single runtime license.

Developer controls: Arc GIS Server provides a common set of developer controls that allow developers to easily deploy wellcrafted applications with a common look and feel. A common user experience leads to a short learning curve for users, so returns on the applications are quickly realized.

Cross platform functionality: Arc GIS Server application and all of its associated objects and controls are available on a wide variety of platforms including Windows, Linux. There is no need to change or add operating environments to the present computing infrastructure.

Dynamic display: It provides a mechanism for synchronized refreshing that allows moving objects, such as maps and graphics, to be displayed with fast refresh-rate technology.
Toolbars provide GIS tools, such as Pan, Zoom, Identify, Selection, and Editing, to interact with maps.

Developer tools: in Arc GIS Server include code projects, wizards, templates, and code snippets that integrate with your integrated development environment (IDE) to help you create custom desktop GIS applications.

\subsection{Application Architecture}

The architecture has been considered for the implementation of Geospatial Map based portal (GMP) is scalable to enterprise DSS with enterprise Geo-database \& VPN connectivity as shown in Fig. 1. Authenticate user access control is ensured by VPN \& database security by using enterprise Geo-database.

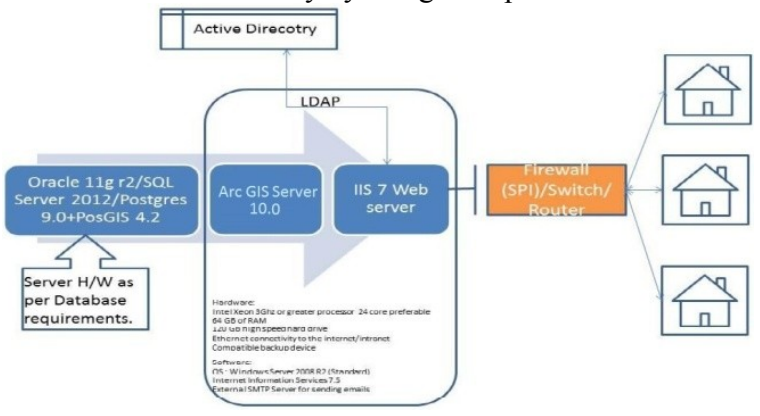

Figure 1 Enterprise Architecture

\subsection{Development Environment}

Arc Objects classes library is used in Server SDK environment using $\mathrm{J} 2 \mathrm{EE}$ as front-end.

\section{DEPLOYMENT ENVIRONMENT}

\subsection{Installation of Arc GIS Server Runtime}

Arc GIS Server software-based applications require that Arc GIS Server Runtime be installed on the end user's machine. Installation of the runtime can be handled in either of two ways:

1. End user runs the Arc GIS Server Runtime setup directly from the CD.

2. Arc GIS Server Runtime setup can be included within our own application's installation program

\subsection{Authorization of the Arc GIS Server Runtime}

The mechanism used to license the Arc GIS Server Developer Kit on a per-machine, single use basis via an ESRI Copy Protection (*.ecp) file.

\subsection{Application Deployment}

After arranging the shape files layers in proper sequence, the map is deployed in web platform by using Arc GIS web application platform.

\section{GEOSPATIAL MAP BASED PORTAL FEATURES}

The following functions have implemented in Geospatial Map based portal (GMP) for user use. These functions have made the geo data more accessible, analyzing in the application.

$>$ Display a map with multiple map layers, such as roads, streams and boundaries.

$>$ Pan and zoom throughout a map. 
$>$ Draw graphic features such as points, lines, ellipses, rectangles and polygons.

$>$ Draw descriptive text.

$>$ Identify features on a map by pointing at them.

$>$ Select features along lines and inside boxes, areas, polygons, and circles.

$>$ Select features within a specified distance of other features

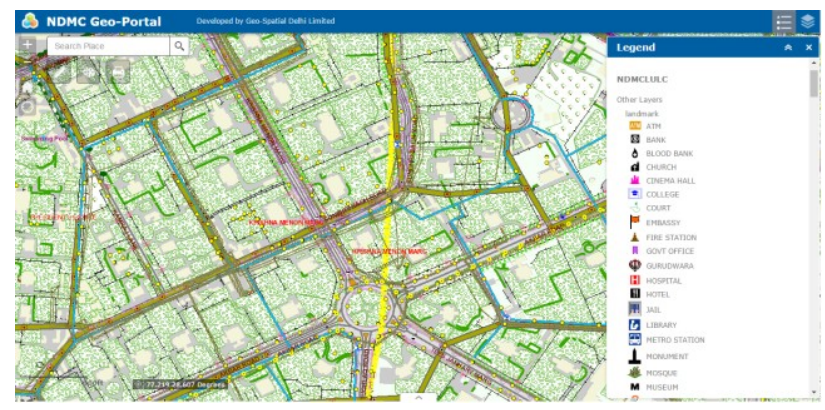

Figure 2 GMP, Front Page (Thematic Map)

User can identify the feature by using the legend. It is the front page it's enabled after filling the user name and password in application opening web page.

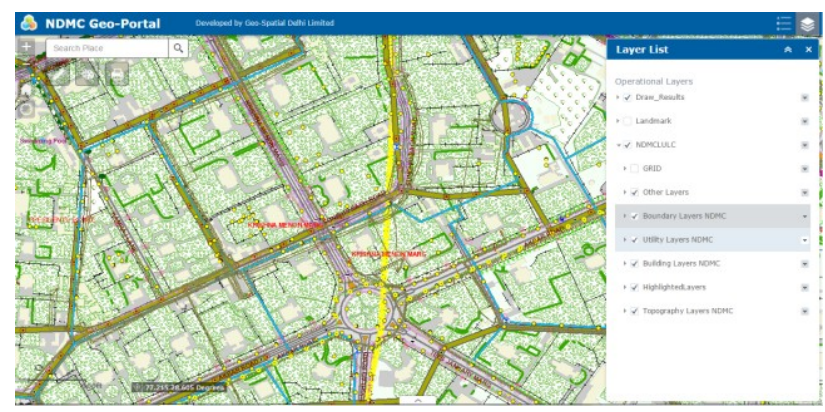

Figure 3 Layer Control

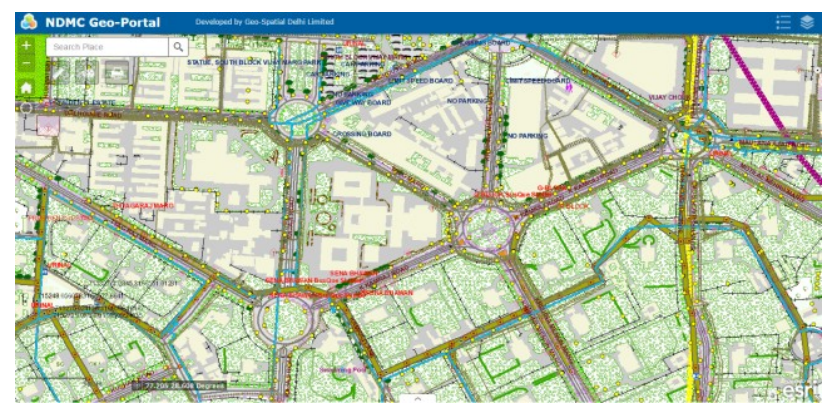

Figure 4 Map View Control

User can control the map view by clicking on zoom-in, zoomout, pan icons.

User can control the layers view. The necessary layers would be switch on and off by clicking on the check button in layer list.

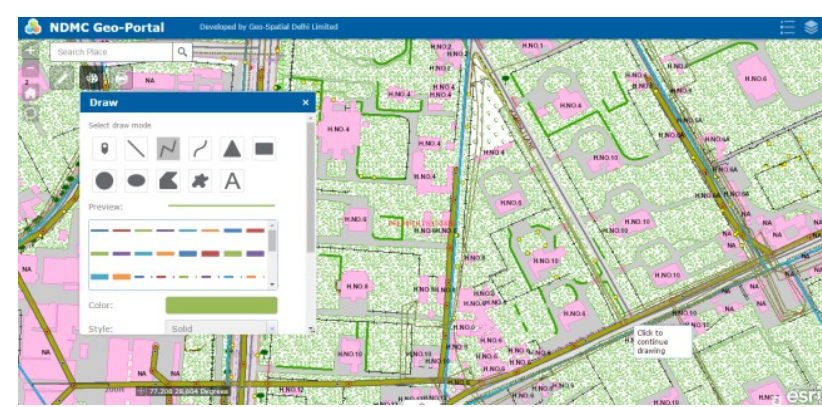

Figure 5 Draw Features

User can draw the spatial features like area, location and roads etc. (Polygon, Line, Point) in map and also fill the pertaining information's of features.

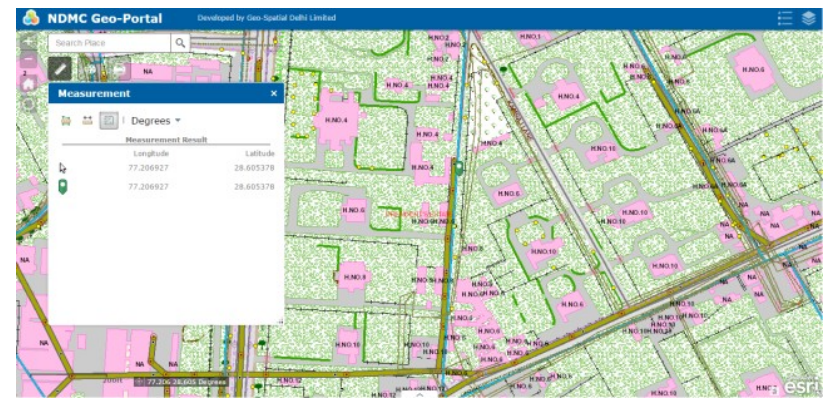

Figure 6 Find and/or Measure location with Lat-Long

User can find the location by putting the location address in search option and/or can view the location info, geographic location of particular location.

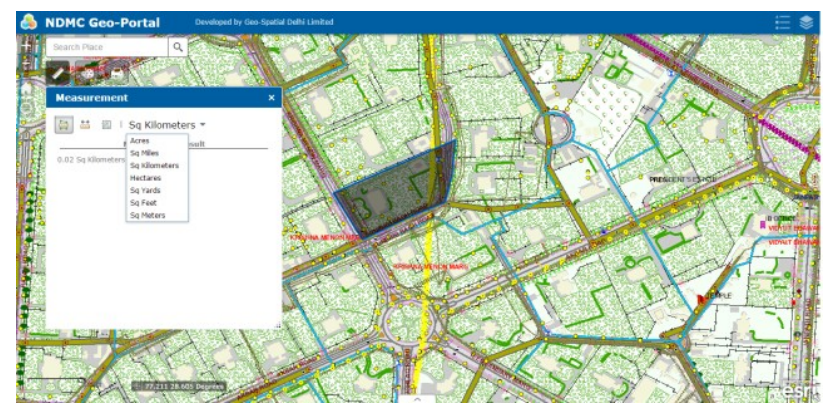

Figure 7 Measure Area

User can measure the area of any location in different area unit by drawing the required area by this tool.

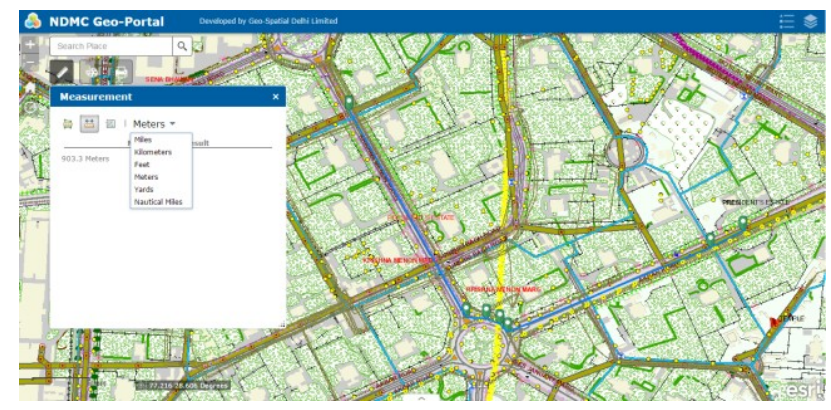

Figure 8 Measure Length 
User can measure the distance of path towards destination where he want to visit. User can find the suitable and short path by using this tool.

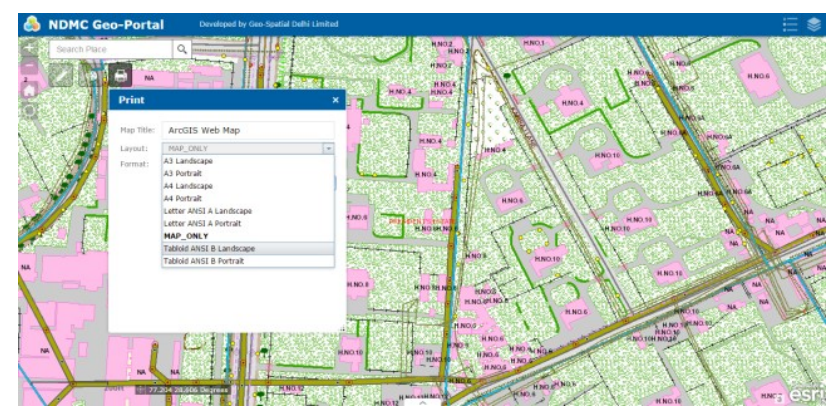

Figure 9 Print Map

User can take the print of required area map in different thematic map sizes in different formats (PDF, JPEG etc.).

\section{CONCLUSION}

This study is a Geospatial Map based portal (GMP) that provides access to spatial datasets pertaining to New Delhi Municipal Council of NCT of Delhi. It is designed to allow viewing, querying, and analysis of geographic information. There are two aspects of the Internet GIS. One is the web-based application and the other is Server/Client balance. This application is a software independent system that users do not have to buy any GIS software and do not have to read manuals to use it but they can access GIS data and analysis functions over the Internet. It offers maximum functionality with the minimum effort.

The drawback in such a distributed system is that data come from different sources based on different forms which cause havoc in a GIS. It is necessary to compile data before the development of the application.

The response time for generating maps is related to the map server configuration (memory, disk, and processor). The map is also depending on the network connection. It can take a while to download the maps. In addition, system downtime for maintenance and updates for a web site is unavoidable. But this system is designed for easy maintenance and repair without interruption.

An entrance page will be created to make a simple presentation of the service. This provides users an option for choosing a specific area of interest to start with. Furthermore, new datasets and functions will be added to the service.

\section{ACKNOWLEDGEMENT}

The authors are thankful to the officials of New Delhi Municipal Council, NCT of Delhi for their constant support and encouragement.

\section{REFERENCES}

Building Enterprise DSS Using ARC GIS Engine Geoamphere: A CASE STUDY, Vivek Chitale, M. Vinayak Rao, Geetanjali Mehta, Dhrubjyoti Sarma, N. Dhanasekar

White paper on Arc Engine 9.2 development (http://resources.esri.com/Arc GISengine) 